\title{
Neutralization versus Compression Plate on Lateral Malleolus Fracture: Is Lag Screw Necessary?
}

\author{
Ahmet Oztermeli', Sinan Karaca ${ }^{2}$, Firat Fidan², Ozgun Karakus ${ }^{3}$ \\ ${ }^{1}$ Department of Orthopaedics and Traumatology, Gebze Fatih Hospital, Kocaeli, Turkey \\ ${ }^{2}$ Department of Orthopaedics and Traumatology, Sancaktepe Ilhan Varank Training and Research Hospital, \\ İstanbul, Turkey \\ ${ }^{3}$ Department of Orthopaedics and Traumatology, Omer Halis Demir University Hospital, Nigde, Turkey \\ Email: ahmetoztermeli@hotmail.com,mdsnn@hotmail.com,drfiratfidan@gmail.com,ozgunkarakus@hotmail.com
}

How to cite this paper: Oztermeli, A., Karaca, S., Fidan, F. and Karakus, O. (2019) Neutralization versus Compression Plate on Lateral Malleolus Fracture: Is Lag Screw Necessary? Open Journal of Orthopedics, 9 , 81-88.

https://doi.org/10.4236/ojo.2019.94008

Received: January 18, 2019

Accepted: March 26, 2019

Published: March 29, 2019

Copyright () 2019 by author(s) and Scientific Research Publishing Inc. This work is licensed under the Creative Commons Attribution International License (CC BY 4.0).

http://creativecommons.org/licenses/by/4.0/

\begin{abstract}
Introduction: Our aim was to compare clinical and radiological results of lateral malleolus fracture treated with neutralization and compression plate. Material and Methods: 54 patients with isolated lateral malleolus fractures treated between March 2012 and April 2015 at Fatih Sultan Mehmet Training and Research Hospital were evaluated with the Ankle-Hindfoot Scale of the American Orthopedic Foot and Ankle Society (AOFAS) score (excellent, $\geq 90$; good, 75 - 89; acceptable, 50 - 74; poor, <50); patient satisfactory score (PSS) (0, very unhappy; 10 , very happy) and weight-bearing walking based a visual analogue scale (VAS) (0, pain-free; 10 , the most unbearable pain). The union of the fractures also evaluated. Results: There was no significant change in AOFAS, VAS, PSS and the union rates between two plating techniques. Conclusion: Similar results have shown both of two plating techniques were successful treating isolated lateral malleolus fracture.
\end{abstract}

\section{Keywords}

Lateral Malleol, Fracture, Ankle Fracture, Lag Screw, Plate Fixation

\section{Introduction}

Lateral malleolus fracture is one of the most common fractures treated surgically [1] [2]. Stable isolated lateral malleolus fractures can be treated conservatively; on the other hand, surgical fixation is the gold standard treatment option for displaced, unstable lateral malleolus fractures [3] [4] [5]. 
Plate application is the most common surgical technique for unstable lateral malleolus fracture treatment [6]. Nowadays, among the orthopedic surgeons, locking compression plate (LCP) use has an increasing popularity for fracture fixation with plates [7]. LCP are commonly used for various fracture types [8] as well as lateral malleolus fracture. Locking plates have different application options such as a compression plate or a neutralization plate [9] [10] [11] [12] [13]. In the neutralization plate technique, firstly fracture line is compressed with a lag screw, then LCP is applied. Fracture line is compressed with an LCP without using a lag srew in the compression plate technique [11] [12] [13] [14]. In the literature, there are several biomechanical studies comparing different plate types and techniques for lateral malleolus fractures. They found similar construct stability and strength to the compression and locking plates [14] [15] [16].

In this study, our aim was to compare clinical and radiological results of lateral malleolus fracture treated with neutralization and compression plate. Our hypothesis was in AO44B1 lateral malleolus fractures, neutralization plate technique using lag screw is not necessary. To our knowledge, this is the first study comparing clinical and radiological results of neutralization and the compression plate techniques using the LCP.

\section{Material and Methods}

Patients with ankle joint fractures treated between March 2012 and April 2015 at our hospital were retrospectively evaluated. The inclusion criteria were patients; isolated unilateral lateral malleolus fracture based on clinical and radiological examination, patients treated with open reduction and internal fixation (neutralization or compression techniques), patients with the ability to ambulate without assistance prior injury, patients who didn't have osteoarthritis before surgery, patients who had at least one year follow-up data and AO type 44B1 fractures. Based on the different fixation techniques, patients were assigned into two groups: 1) Group A (26 patients): treated with neutralization plate (Figure 1); 2) Group B (28 patients): treated with compression plate (Figure 2).

Patients have been evaluated with the Ankle-Hindfoot Scale of the American Orthopedic Foot and Ankle Society (AOFAS) score (excellent, $\geq 90$; good, 75 89; acceptable, 50 - 74; poor, $<50$ ); patient satisfactory score (PSS) (0: very unhappy-10: very happy) and weight-bearing walking based a visual analogue scale (VAS) (0: pain-free-10: the most unbearable pain).

The union of the lateral malleolus fracture has been evaluated with the two dimension ankle plain radiography (anterior-posterior (AP), lateral). Radiographic union was defined as the complete disappearance of fracture lines in the AP and lateral view. Radiographic bone union was determined by a single orthopedic surgeon who was blinded to the aim and protocol of this study. The rate of radiographic union was compared postoperatively between the two groups at 3 months follow up. 


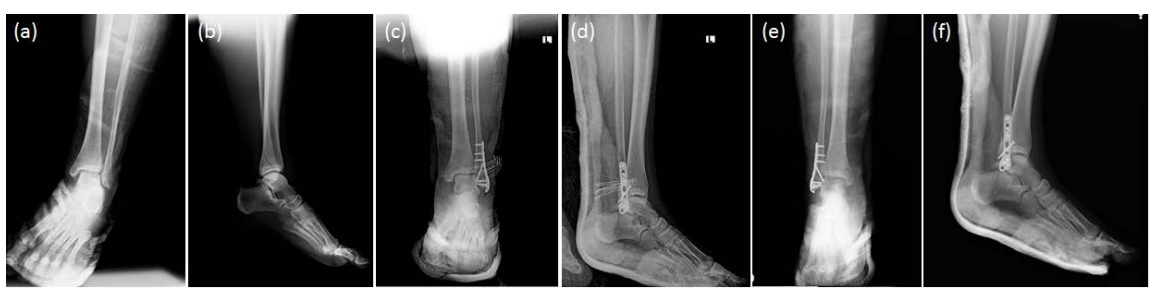

Figure 1. Lateral malleolus fracture fixated with a neutralization plate. (a) Preoperative anteroposterior X-ray (b) preoperative lateral X-ray (c) Postoperative anteroposterior X-ray (d) preoperative lateral X-ray (e) postoperative 3 months anteroposterior X-ray (f) postoperative 3 months lateral X-ray.
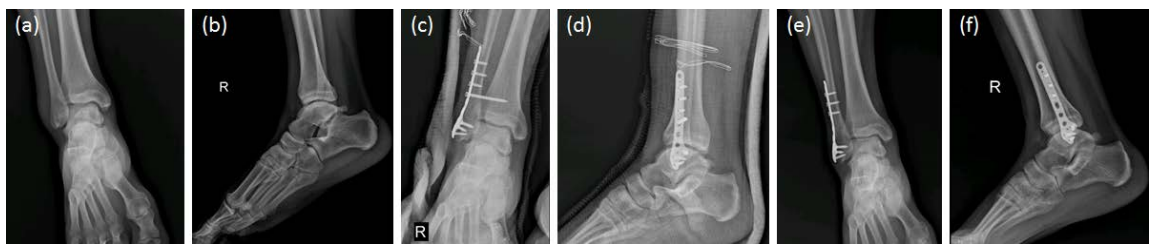

Figure 2. Lateral malleolus fracture fixated with a compression plate. (a) Preoperative anteroposterior X-ray (b) preoperative lateral X-ray (c) Postoperative anteroposterior X-ray (d) postoperative lateral X-ray (e) postoperative 3 months anteroposterior X-ray (f) postoperative 3 months lateral X-ray.

\subsection{Surgical Procedure}

All patients had the surgery under spinal anesthesia. One hour before the surgical procedure antibiotic prophylaxis was given (1 gr cefazolin). Pneumatic tourniquet was used to control the bleeding at the surgical area during the surgery. The lateral malleolus fracture was reduced by direct open reduction. In both groups, the amount of periosteal elevation was maintained to the minimum required for anatomical reduction. In Group A after anatomic fracture reduction lag screw was inserted and the locking neutralization plate was placed on lateral aspect of lateral malleolus under fluoroscopic control. In Group B after anatomic fracture reduction, LCP was placed on lateral aspect of lateral malleolus under fluoroscopic control.

After internal fixation of lateral malleolus, sydesmosis diastases was measured by using the Cotton's test under fluoroscopy with a bone hook [17] $2 \mathrm{~mm}$ widening of syndesmosis under a lateral force to the distal fibula considered abnormal. A syndesmotic fixation screw was used with the ankle joint in 10 degree of dorsiflexion to maintain the stability.

\subsection{Postoperative Care}

There was no difference with the postoperative care between two groups. Weight-bearing was not allowed for three weeks postoperatively. At six weeks postoperatively full weight-bearing was allowed. A splint below the knee was applied to all patients postoperatively three weeks.

For antibiotic prophylaxis, cefazolin $1 \mathrm{gr}$ was given intravenously every eight hours for 24 hours postoperatively. After proper wound healing was seen post- 
operative follow-up was undertaken at three, and 12 months and all study patients were clinically and radiographically evaluated.

For the statistical analyzes, the IBM SPSS Statistics 22 (IBM SPSS, Turkey) program was used while assessing the findings of the study. When the study data were evaluated, the normal distribution of the parameters was evaluated by the Shapiro Wilks test. While descriptive statistical methods (Mean, Standard deviation, frequency) as well as quantitative data were evaluated; Student $t$ test was used for differences between the two groups for parameters that was normally distributed, Mann Whitney $U$ test was used for differences between the two groups for parameters that was not normally distributed. Fisher's Exact test and Continuity (Yates) correction were used to compare qualitative data. Significance was assessed at $\mathrm{p}<0.05$.

\section{Results}

In this retrospective study 54 patients with $\mathrm{AO} 44 \mathrm{~B} 1$ fracture and eligible for inclusion criteria were evaluated. There were 26 patients in group A and 28 patients in group B. Patient's age were between 18 and 47 (30.06 \pm 8.23$) .38$ patients were male and 16 patients were female. 22 patients were smoker and 8 patients had history of diabetes mellitus (DM). 26 patients had right side and 28 patients had left side ankle fracture. There was no significant changes in patients demographic data between two groups in terms of age, weight, BMI, diabetes mellitus history or smoker ratio. Also no significant difference noted in time from injury to surgery, syndesmosis screw usage rate and side of injury. The follow up time was 12 to 18 months and there was no significant difference between two groups in follow up time (Table 1).

The mean VAS score was $8.08 \pm 1.06$ in Group A and $8.32 \pm 1.28$ in Group B. There was no significant statistic changes between two groups $(p>0.05)$. The mean AOFAS scores was 84.77 \pm 9.3 in Group A and $87.46 \pm 11.02$ in Group B and no significant changes was found between two groups ( $p>0.05$ ). In Group A the mean PSS was $8.31 \pm 1.1$ in Group B the mean PSS was $8.64 \pm 1.25$ there was no significant changes between two groups $(p>0.05)$ (Table 2).

In Group A one patient had a superficial wound infection that healed with oral antibiotics for seven days. No loss of reduction occurred on radiographic follow up, and no hardware irritation or failure was seen. In all patients union of fracture was achieved in three months clinically.

\section{Discussion}

Unstable and closed lateral malleolus fractures are mostly seen in young and active patients caused by a minor trauma [18]. Stabilization of lateral malleolus is essential for these young and active patients with high expectation of activity. Surgical treatment is the gold standard treatment option [19] [20]. Fixation may be achieved in several surgical ways ranging from minimal invasive closed techniques to open techniques [21]. Open techniques varies from conventional plates to LCP. The optimal fixation method is still controversial. 
Table 1. Demographic and characteristic of patients.

\begin{tabular}{|c|c|c|c|}
\hline & Group A & Group B & \multirow{2}{*}{$\mathrm{p}$} \\
\hline & Mean \pm SD & Mean \pm SD & \\
\hline Age & $29.73 \pm 7.25$ & $30.36 \pm 9.17$ & ${ }^{1} 0.783$ \\
\hline Time from injury to surgery & $4.69 \pm 1.67$ & $4.64 \pm 1.57$ & ${ }^{1} 0.911$ \\
\hline Follow up time & $14.12 \pm 1.66$ & $14.04 \pm 1.86$ & ${ }^{1} 0.869$ \\
\hline Weight & $76.58 \pm 13.88$ & $81.32 \pm 15.74$ & ${ }^{1} 0.247$ \\
\hline Syndesmosis screw usage & $10(\% 38.4)$ & $11(\% 39.3)$ & ${ }^{2} 1.000$ \\
\hline BMI & $24.5 \pm 4.56$ & $24.96 \pm 4.29$ & ${ }^{1} 0.702$ \\
\hline \multicolumn{4}{|l|}{$\operatorname{Sex} n(\%)$} \\
\hline Male & $19(\% 73.1)$ & $19(\% 67.9)$ & \multirow{2}{*}{${ }^{2} 0.903$} \\
\hline Female & $7(\% 26.9)$ & $9(\% 32.1)$ & \\
\hline \multicolumn{4}{|l|}{ Side $n(\%)$} \\
\hline Right & $13(\% 50)$ & $13(\% 46.4)$ & \multirow{2}{*}{${ }^{2} 1.000$} \\
\hline Left & $13(\% 50)$ & $15(\% 53.6)$ & \\
\hline \multicolumn{4}{|l|}{$\mathrm{DM} n(\%)$} \\
\hline No & $22(\% 84.6)$ & $24(\% 85.7)$ & \multirow{2}{*}{${ }^{3} 1.000$} \\
\hline Yes & $4(\% 15.4)$ & $4(\% 14.3)$ & \\
\hline \multicolumn{4}{|l|}{ Smoking $n(\%)$} \\
\hline No & $15(\% 57.7)$ & $17(\% 60.7)$ & \multirow{2}{*}{${ }^{2} 1.000$} \\
\hline Yes & $11(\% 42.3)$ & $11(\% 39.3)$ & \\
\hline
\end{tabular}

${ }^{1}$ Student $\mathrm{t}$ Test; ${ }^{2}$ Continuity (Yates) Correction; ${ }^{3}$ Fisher's Exact Test.

Table 2. Bone union rates, VAS, AOFAS and PSS.

\begin{tabular}{cccc}
\hline & Group A & Group B & \multirow{2}{*}{$\mathrm{p}$} \\
\cline { 2 - 3 } & Mean \pm SD & Mean \pm SD & \\
\hline Bone union rates & $4.69 \pm 1.67$ & $4.64 \pm 1.57$ & ${ }^{1} 0.911$ \\
VAS & $8.08 \pm 1.06$ & $8.32 \pm 1.28$ & ${ }^{2} 0.328$ \\
AOFAS & $84.77 \pm 9.3$ & $87.46 \pm 11.02$ & ${ }^{1} 0.338$ \\
PSS & $8.31 \pm 1.19$ & $8.64 \pm 1.25$ & ${ }^{2} 0.205$ \\
\hline
\end{tabular}

${ }^{1}$ Student $\mathrm{t}$ Test; ${ }^{2}$ Mann Whitney U Test.

In this study, 54 patients surgically fixated with compression plate or neutralization plate using LCP were evaluated. There were no statistically significant differences in functional outcome comparing these two techniques. There was no significant difference between two groups according to radiographical results. Y. Asloum et al. found 3\% nonunion rate in surgically treated lateral malleolus fractures [21]. In our study there was no patient with nonunion. However in this study the nonunion cases were seen in elder patients. Our study based on younger patients and this could cause the little difference of union rates. 
Schepers $\mathrm{T}$ et al. investigated wound complications of lateral malleolus fractures comparing conventional plate and LCP; showed higher wound complication rates in LCP (17.5\%) [22]. We had only one patient with a superficial wound infection and treated with oral antibiotics for seven days. We found no difference in VAS, AOFAS and PSS between two groups and we noted excellent results. Our results were similar with Huang et al. who investigated three implant systems and found better results with LCP technique than conventional techniques in term of AOFAS.

In this study, satisfactory functional outcomes and pace of recovery were achieved with both neutralization plate technique and compression plate technique.

Our study had limitations. Firstly, it was a retrospective study. Secondly the study group size was small. Also, the research assistants involved in the data collection of this study were not blinded to treatment type and which may have introduced a bias. Finally, the length of follow-up in this study was another limitation. It is possible that with longer term follow up, the posttraumatic arthritis could begin to impact function.

\section{Conclusion}

In conclusion, surgical fixation of unstable lateral malleolus fracture is one of the most commonly used treatment option in orthopedic practice. Although many surgical options have been advocated to treat these fractures; the optimal fixation method is still controversial.

\section{Conflicts of Interest}

The authors declare no conflicts of interest regarding the publication of this paper.

\section{References}

[1] Peter, J.D., Robert, H.F., Joseph, L.M. and Duane, M.L. (1987) Epidemiology of Ankle Fractures in Rochester, Minnesota. Acta Orthopaedica Scandinavica, 58, 539-544. https://doi.org/10.3109/17453678709146395

[2] Court-Brown, C.M., McBirnie, J. and Wilson, G. (1998) Adult Ankle Fractures an Increasing Problem? Acta Orthopaedica Scandinavica, 69, 43-47. https://doi.org/10.3109/17453679809002355

[3] Hughes, J.L., Weber, H., Willenegger, H. and Kuner, E.H. (1979) Evaluation of Ankle Fractures: Non-Operative and Operative Treatment. Clinical Orthopaedics and Related Research, 138, 111-119.

[4] Rukavina, A. (1998) The Role of Fibular Length and the Width of the Ankle Mortise in Posttraumatic Osteoarthrosis after Malleolar Fracture. International Orthopaedics, 22, 357-360. https://doi.org/10.1007/s002640050277

[5] Thordarson, D.B., Motamed, S., Hedman, T., Ebramzadeh, E. and Bakshian, S. (1997) The Effect of Fibular Malreduction on Contact Pressures in an Ankle Fracture Malunion Model. The Journal of Bone and Joint Surgery (American Volume), 79, 1809-1815. 
https://doi.org/10.2106/00004623-199712000-00006

[6] Sanders, D.W., Tieszer, C. and Corbett, B. (2012) Operative versus Nonoperative Treatment of Unstable Lateral Malleolar Fractures: A Randomized Multicenter Trial. Journal of Orthopaedic Trauma, 26, 129-134. https://doi.org/10.1097/BOT.0b013e3182460837

[7] Sommer, C., Gautier, E., Müller, M., Helfet, D.L. and Wagner, M. (2003) First Clinical Results of the Locking Compression Plate (LCP). Injury, 34, 43-54. https://doi.org/10.1016/j.injury.2003.09.024

[8] Wagner, M. (2003) General Principles for the Clinical Use of the LCP. Injury, 34, 31-42. https://doi.org/10.1016/j.injury.2003.09.023

[9] Smith, W., Stahel, P., Ziran, B. and Anglen, J. (2007) Locking Plates: Tips and Tricks. The Journal of Bone and Joint Surgery-American Volume, 89, 2298-2307. https://doi.org/10.2106/00004623-200710000-00028

[10] Fridberg, M., BanZaid, I., Issa, Z., Krasheninnikoff, M. and Troelsen, A. (2013) Locking Plate Osteosynthesis of Clavicle Fractures: Complication and Reoperation Rates in One Hundred and Five Consecutive Cases. International Orthopaedics, 37, 689-692. https://doi.org/10.1007/s00264-013-1793-9

[11] Joeris, A., Audigé, L., Ziebarth, K. and Slongo, T. (2012) The Locking Compression Paediatric Hip Plate: Technical Guide and Critical Analysis. International Orthopaedics, 36, 2299-2306. https://doi.org/10.1007/s00264-012-1643-1

[12] Nikolaou, V.S., Tan, H.B., Haidukewych, G., Kanakaris, N. and Giannoudis,P.V. (2011) Proximal Tibial Fractures: Early Experience Using Polyaxial Locking-Plate Technology. International Orthopaedics, 35, 1215-1221. https://doi.org/10.1007/s00264-010-1153-y

[13] Gupta, R.K., Rohilla, R.K., Sangwan, K., Singh, V. and Walia, S. (2010) Locking Plate Fixation in Distal Metaphyseal Tibial Fractures: Series of 79 Patients. International Orthopaedic, 34, 1285-1290. https://doi.org/10.1007/s00264-009-0880-4

[14] Knutsen, A.R., et al. (2016) Distal Fibula Fracture Fixation: Biomechanical Evaluation of Three Different Fixation Implants. Foot and Ankle Surgery, 22, 278-285. https://doi.org/10.1016/j.fas.2016.08.007

[15] Huang, Z.Y., et al. (2014) Comparison of Three Plate System for Lateral Malleolar Fixation. BMC Musculoskeletal Disorders, 15, 360.

[16] Bariteau, J.T., et al. (2014) A Biomechanical Evaluation of Locked Plating for Distal Fibula Fractures in an Osteoporotic Sawbone Model. Foot and Ankle Surgery, 20, 44-47. https://doi.org/10.1016/j.fas.2013.10.004

[17] Cotton, F.J. (1910) Fractures and Joint Dislocations. WB Saunders, Philadelphia, 549.

[18] Lamontagne, J., Blachut, P.A., Broekhuyse, H.M., O’Brien, P.J. and Meek, R.N. (2002) Surgical Treatment of a Displaced Lateral Malleolus Fracture: The Antiglide Technique versus Lateral Plate Fixation. Journal of Orthopaedic Trauma, 16, 498-502. https://doi.org/10.1097/00005131-200208000-00008

[19] Yde, J. and Kristensen, K.D. (1980) Ankle Fractures: Supination-Eversion Fractures of Stage IV: Primary and Late Results of Operative and Non-Operative Treatment. Acta Orthopaedica Scandinavica, 51, 695-702. https://doi.org/10.3109/17453678008990904

[20] Bauer, M., Bergström, B., Hemborg, A. and Sandegård, J. (1985) Malleolar Fractures: Nonoperative versus Operative Treatment: A Controlled Study. Clinical Orthopaedics and Related, 199, 17-27. 
https://doi.org/10.1097/00003086-198510000-00004

[21] Asloum, Y., Bedin, B., Roger, T. Charissoux, J.L., Arnaud, J.P., and Mabit, C. (2014) Internal Fixation of the Fibula in Ankle Fractures. A Prospective, Randomized and Comparative Study: Plating versus Nailing. Orthopaedics and Traumatology: Surgery and Research, 100, 255-259. https://doi.org/10.1016/j.otsr.2014.03.005

[22] Schepers, T., Lieshout, E.M. Vries, M.R. and Van der Elst, M. (2011) Increased Rates of Wound Complications with Locking Plates in Distal Fibular Fractures. Injury, 42, 1125-1129. https://doi.org/10.1016/j.injury.2011.01.009 